\title{
Modelling and Experimental Research in Hot Precision Forging of Duplicate Gear Blank
}

\author{
Zhi Li ${ }^{1, \text { a }}$, Baoyu Wang ${ }^{1, b}$ \\ ${ }^{1}$ School of Mechanical Engineering, University of Science and Technology Beijing, Beijing 100083, \\ China; \\ adazhi0120@163.com, bbywang@ustb.edu.cn
}

Keywords: duplicate gear blank, precision forging, FE simulation.

\begin{abstract}
In this paper, two-steps forging is used to manufacture duplicate gear blank. The simulating of the second step forging process is based on DEFORM which is a finite element software. The forming parameter range was determined while the forging force was predicted. Using a set experiment tool of closed-die forging, teeth of forged duplicate gear blank were well filled. The influence of transition product diameter and the thickness and height of wad are researched. Too small diameter of transition product will affect the quality of the product, so the first step of forging should rigorously control the diameter of the transition product. The wad thickness has great influence on the final forging force, while the effect of the wad height is relatively small.
\end{abstract}

\section{Introduction}

Duplicate gear is an important transmission part in the automotive transmission, which consists of a set of spur gear and a set of helical gear. As the diameter of the spur gear is less than that of the helical gear, it is difficult to use the general cutting method to process the machining process as a whole. In order to solve this problem, the spur gear and helical gear are manufactured respectively and welded together in the general production method [1]. The disadvantages of this method are complex technology and long processing cycle. The welding part is subjected to a lot of shear stress which reduces the strength of the part during running process.

Two-steps forging is used to manufacture duplicate gear blank, which means spur gear is forged during this process and the helical gear will be cut in the follow-up process [2]. The advantages of gear forging include reducing manufacturing costs and saving materials, better mechanical properties, and increasing productivity [3]. The production of gears using the net-shape forging technique has become a hot topic in recent years [4-6]. Due to the complex structure of duplicate gear blank, the experimental and simulation method are used to analyze the forging process in this paper. Thus the main aim of the research is to investigate the influence of transition product diameter and the thickness and height of wad.

\section{Experimental Technique}

A duplicate gear blank is illustrated in Figure 1 with characteristic parameters of spur gear listed in Table 1. Due to complex construction of the gear blank, two-steps forging is the optimal process choice, and technological process is shown in Figure 2。

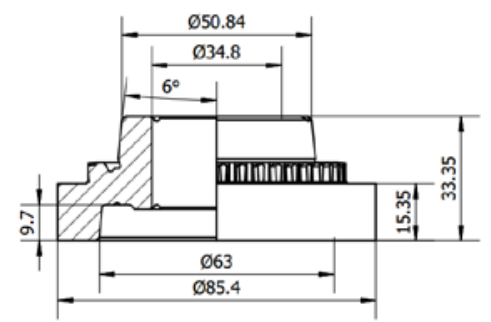

Fig. 1 Geometry of the duplicate gear blank (Dimensions are in $\mathrm{mm}$ ). 
Table1: Characteristic parameters of spur gear of the duplicate gear blank

\begin{tabular}{ll}
\hline Parameters & Value \\
\hline Number of teeth & 42 \\
Module $(\mathrm{mm})$ & 1.61 \\
Pressure angle $\left({ }^{\circ}\right)$ & 20 \\
Tip diameter $(\mathrm{mm})$ & 69.05 \\
Root diameter $(\mathrm{mm})$ & 65.2 \\
\hline
\end{tabular}

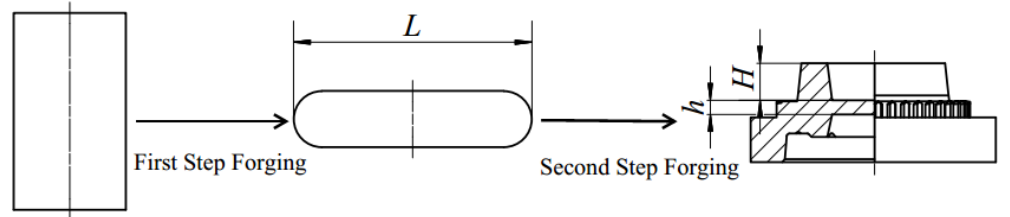

Fig. 2 Schematic diagram of two-step forging.

The first forging is free-forging process that do not need die during forging. Transition product diameter $L$ is an important parameter to affect product quality, so it's necessary to control the stroke . The die of second step forging is a set tool of closed-die forging, and the details of the tool set is shown in Figure 3(a).

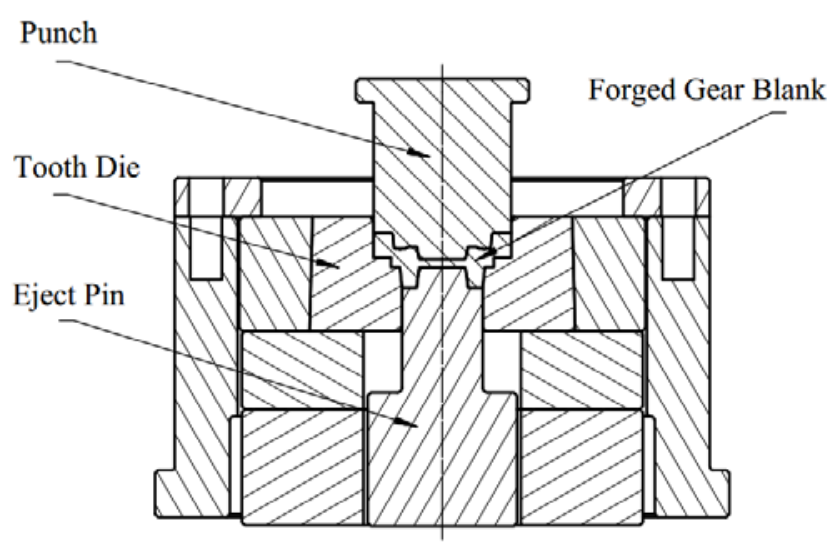

(a) Illustration of tool setup

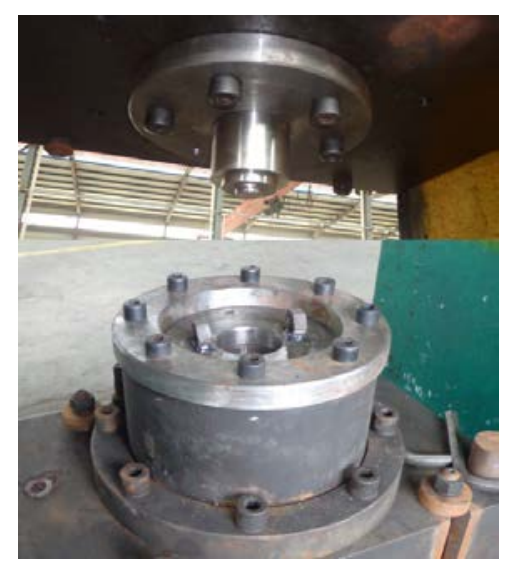

(b) Foging tool

Fig. 3 Tool and setup for the second forging of the duplicate gear blank

The gear blank was forged under a 1000 ton friction press at a rate of $200 \mathrm{~mm} / \mathrm{second}$ and a die set was installed. What is shown in Figure 3 is the initial tooling setup for the hot forging. All tool surfaces in contact with the workpiece was covered with water-based graphite lubricant. The workpiece was heated to $1100^{\circ} \mathrm{C}$ before the first forging, and die was preheated to about $150^{\circ} \mathrm{C}$.

\section{FE model and Numerical Procedures}

3D FE simulation has been carried out to the further evaluation of the material flow and teeth filling for the forging of the duplicate gear blank. We used PRO/E software system to establish a 3D FE model of the die and the first step forged blank of the gear blank. Finite Element simulation of the forging process was carried out using DEFORM-3D. The FE model was shown in figure 4 . Due to symmetry, just one-fourteenth of the model was used. In order to reduce computer CPU time, the forging dies are considered to be rigid and the workpiece material is rigid-plastic, respectively. The workpiece was meshed with 26,774 four nodes tetrahedral elements initially and automatic re-meshing occurs during the process of simulation. A low-carbon alloy steel, 42CrMo4 (AISI 4140) was used as the material of the workpiece in the current study. And it was heated to $1000^{\circ} \mathrm{C}$. Forging speed was $200 \mathrm{~mm} / \mathrm{sec}$, and the die was preheated to $150^{\circ} \mathrm{C}$. At the hot forging condition, the friction 
conditions prevailing at the interface of die-workpiece was 0.3 . The value of heat transfer coefficient between workpiece and dies was $5 / \mathrm{N} / \mathrm{Sec} / \mathrm{mm} /{ }^{\circ} \mathrm{C}[6]$.

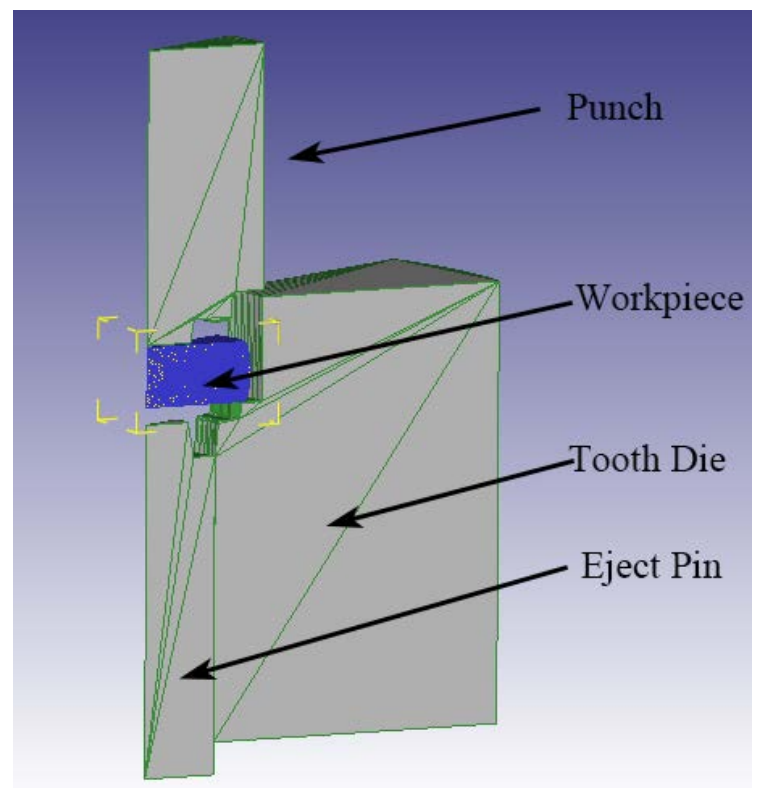

Fig. 4 A 3D FE model with defined symetric planes.

\section{Results and Analysis}

\subsection{Forging Process.}

In the hot forging process, the boundary points of $40 \%$ stroke and $95 \%$ stroke can separate the deformation process of workpiece into three stages. The die filling and the deformation process of the workpiece during the duplicate gear blank forging was shown in Figure 5.

Figure 6 shows forging forces of FE modelling for the forging of the duplicate gear blank. As the teeth are close to be filled, the forging force rises rapidly. The maximum forging force of FE simulation is $6907 \mathrm{KN}$. The history of the FE load shows the same three stages.

The initial deformation stage ( $0 \sim 40 \%$ of stroke): the workpiece is deformed to contact with the die. The metal do not flow in the tooth cavity, so the forging force is very small, less than $300 \mathrm{KN}$

The second stage (40 95\% of stroke): there were two plastic deformation modes at the same time in this stage, i.e. counter extrusion deformation on the disk portions, and the teeth formation at the designed location. The teeth were formed gradually as the punch moves down. So forging force increased significantly and is more than $2000 \mathrm{KN}$.

The third stage (95 100\% of the stroke): metal flows continuously, and all of the interspaces were filled .Because of the sharply decreased free surface, the forging force quickly climbs to $6907 \mathrm{KN}$ at the end of process. . Figure 7 shows that the gear teeth has been completely formed with a little flash around the parting surface.

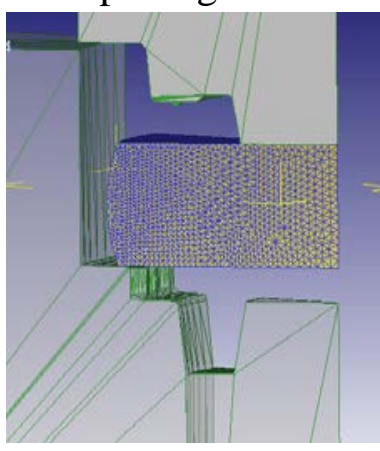

$0 \%$

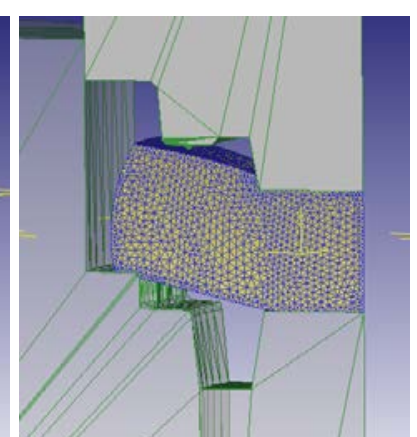

$40 \%$

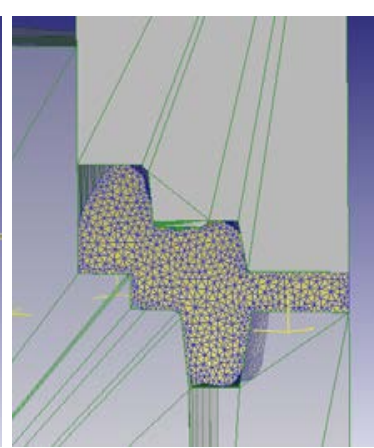

$95 \%$

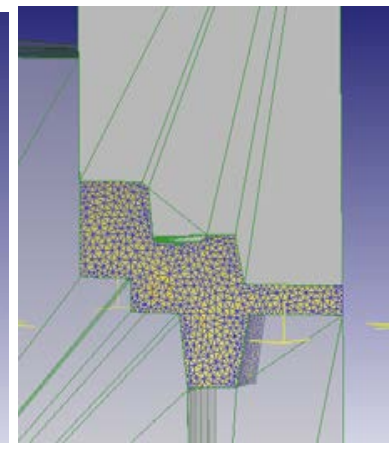

$100 \%$

Fig.5 Simulation results of the die filling process in the hot forging of the duplicate gear blank 


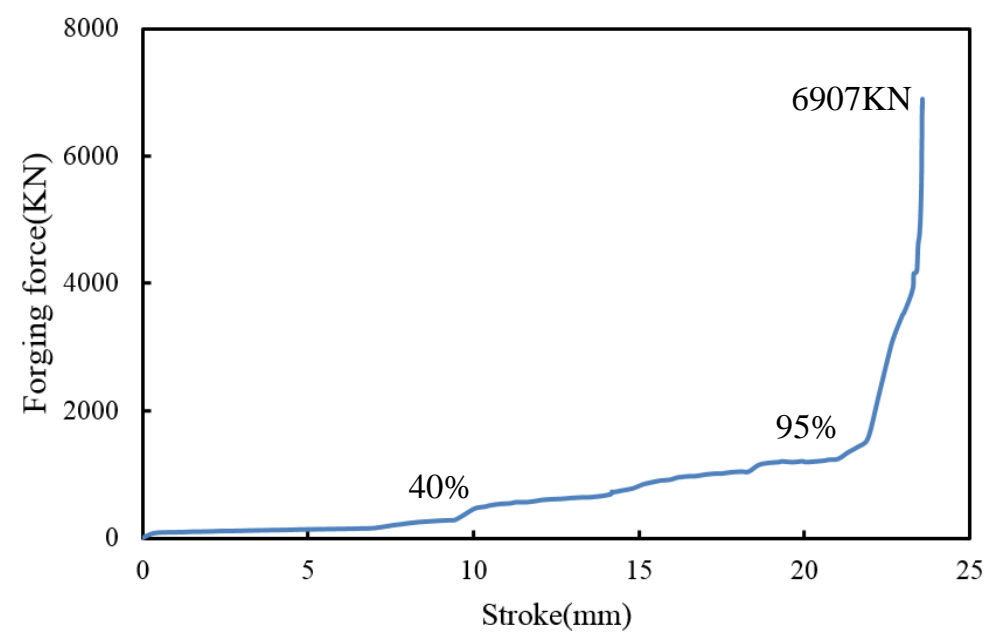

Fig. 6 FE predicted forging forces.

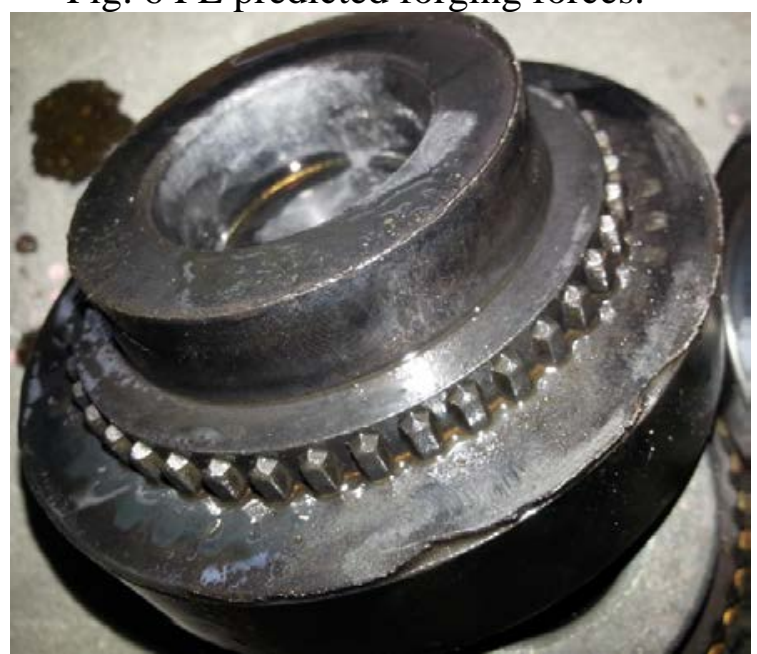

Fig. 7 The forged duplicate gear blank

\subsection{Effect of transition product diameter $L$}

Transition product is manufactured by first step forging, which is billet of the second forging. The dimension of transition product influence product quality. With the same volume, transition product diameter $\mathrm{L}$ were 70, 75, 80 and $85 \mathrm{~mm}$. The results show that the forging load increases with the decrease of diameter, as shown in Table 2. The reason is that smaller diameter of the metal requires more radial flow. And complex structure of duplicate gear blank leads metal flow difficult, so more energy is needed. Results of experimental and simulation show that qualified product can not be produced when the diameter is $70 \mathrm{~mm}$, so the first step of forging should rigorously control the diameter of the transition product.

Table 2 Effect of transition product diameter

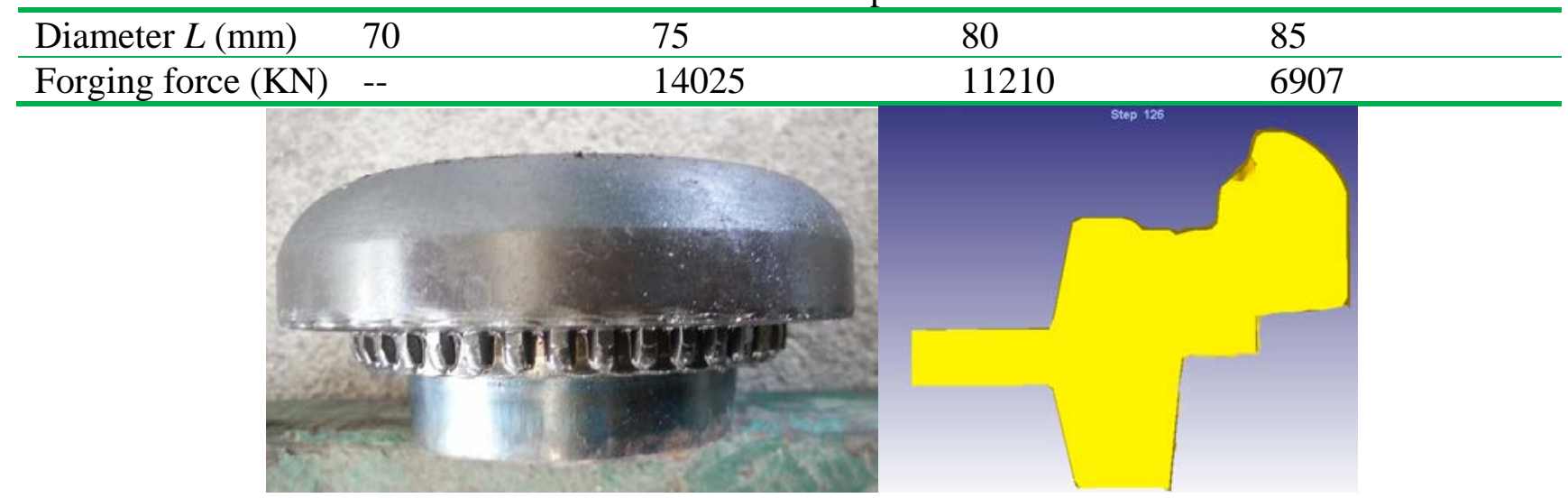

Fig. 8 Filling defect $(\mathrm{L}=70)$ 


\subsection{Effect of wad}

Solid billet is bound to lead appearance of wad in axle hole after forging, which can be removed by stamping. But the wad will affect the metal flow in the forging process, which need to be optimized.

The wad thickness $h$ (Fig.2) is a very important parameter, which affect final forging force and metal usage. In table 3 , it can be seen that small wad thickness will produce relatively large final forging force. The reason is that the metal becomes thin and mobility is reduced, so the radial flow of the metal is difficult. The forging force changes little when the wad thickness is thick, which significantly increased when wad thickness $h$ is $4 \mathrm{~mm}$. Comprehensive consideration of force and saving material, wad thickness $h=5 \mathrm{~mm}$ is the optimal choice.

Table 3 Effect of wad thickness

\begin{tabular}{lllll}
\hline Wad thickness $h(\mathrm{~mm})$ & 4 & 5 & 6 & 7 \\
\hline Final forging force (KN) & 11347 & 6907 & 6481 & 6308 \\
Metal usage (\%) & 99.24 & 100 & 100.76 & 101.53 \\
\hline
\end{tabular}

In the second step of forging, duplicate gear blank was inverted, and the wad height $H$ is shown in Figure 2. It can be seen that the position of the wad does not have a definite effect on the forging force in table 4. The wad height only changes the flow direction of central metal, and there is no obvious change in the flow resistance, so wad height can not affect the final forging force. In order to blance die force, the symmetrical position $(H=11 \mathrm{~mm})$ is chosed.

Table 4 Effect of wad height

\begin{tabular}{lllll}
\hline Wad height $H(\mathrm{~mm})$ & 9 & 11 & 12 & 14 \\
\hline Final forging force $(\mathrm{KN})$ & 6859 & 6536 & 6907 & 6638 \\
\hline
\end{tabular}

\section{Summary}

A two-steps forging process was used to manufacture duplicate gear blank. Teeth of forged duplicate gear blank were well filled. Through the analysis of FE simulation and experimental results, the second step deformation process of forging duplicate gear blank could be separated into three deformation stages. Too small diameter of transition product will affect the quality of the product, so the first step of forging should rigorously control the diameter of the transition product. The wad thickness has great influence on the final forging force, and the effect of the wad height is relatively small.

\section{ACKNOWLEDGEMENTS}

The research is financed by National Natural Science Foundation of China (NSFC)(51375042). Authors also acknowledge the support from Shandong Zhongxing Auto Parts Ltd Company, China, for providing test materials, duplicate gear blank design and forging facilities for the forming trials.

\section{References}

[1]. Wang Li. Research on precision forging process for pre-forging combined gear. Forging and Stamping Technology. Vol. 40 (2015) No. 4, p. 9-13.

[2]. Luo Jing. Research on precision forming and the key technology of the die for auto transmission conjunction gear (master degree, Chongqing University of Technology, China, 2012). p. 23.

[3]. Behrens B. A. and D. Odening. Process and tool design for precision forging of geared components. International Journal of Material Forming, Vol. 2(2009) No. 1, p. 125-128.

[4]. Dean T. A. The net-shape forming of gears. Materials \& Design, Vol. 21(2000) No. 4, p. 271-278. 
[5]. Choi J. C., Y. Choi. Precision forging of spur gears with inside relief. International Journal of Machine Tools and Manufacture, Vol. 39(1999) No. 10, p. 1575-1588.

[6]. Behrens B. A., E. Doege, S. Reinsch, K. et al. Precision forging processes for high-duty automotive components. Journal of materials processing technology, Vol. 185(2007) No. 1, p. 139-146

[7]. Zhang Q. Numerical Simulation of Analysis Parameters in Precision Forging of Spur Gears. China Mechanical Engineering. Vol. 15(2004) No. 17, p. 1546-1548 